\title{
Assessing the effect of risk factors on rates of obstetric transfusion over time using two methodological approaches
}

Edward Jegasothy ${ }^{1,2,5^{*}}$ (D) Jillian Patterson ${ }^{1,3}$, Deborah Randall ${ }^{1,3}$, Tanya A. Nippita ${ }^{1,3,4}$, Judy M. Simpson ${ }^{5}$, David O. Irving ${ }^{6}$ and Jane B. Ford ${ }^{1,3}$

\begin{abstract}
Background: While red blood cell transfusion rates have declined in most Australian medical specialties, obstetric transfusion rates have instead been increasing. Obstetric transfusions are mostly linked to postpartum haemorrhage, the rates of which have also increased over time. This study used two methodological approaches to investigate recent trends in obstetric transfusion in New South Wales (NSW) and the extent to which this was influenced by changing maternal and pregnancy characteristics.

Methods: Linked birth and hospital records were used to examine rates of red blood cell transfusion in the postpartum period for mothers giving birth in NSW hospitals from 2005 to 2015. Logistic regression models were run to examine the contribution of maternal and pregnancy risk factors to changing rates of transfusion. Risk factors were divided into "pre-pregnancy" and "pregnancy related". Crude and adjusted estimates of the effect of year of birth on obstetric transfusion rates were compared to assess the effect of risk factors on rates over time using two approaches. The first compared actual and predicted odds ratios of transfusion for each year. The second compared the observed increase in transfusion rate with that predicted after controlling for the risk factors.

Results: Among 935,659 births, the rate of obstetric transfusion rose from 13 per 1000 births in 2005 to 17 in 2011, and remained stable until 2015. From 2005 to 2015, postpartum haemorrhage increased from 74 to 114 per 1000 births. Compared with the rate in 2005, the available maternal and pregnancy characteristics only partially explained the change in rate of transfusion by 2015 (Method 1, crude odds ratio 1.39 (95\% Cl 1.25, 1.56); adjusted odds ratio $1.29(95 \% \mathrm{Cl} 1.15,1.45)$ ). After adjustment for maternal and pregnancy characteristics, obstetric transfusion incidence was predicted to increase by 10.3\%, but a 38.7\% increase was observed (Method 2).

Conclusion: Rates of obstetric transfusion have stabilised after a period of increase. The trend could not be fully explained by measured maternal and pregnancy characteristics with either of the two approaches. Further investigation of rates and maternal and clinical risk factors will help to inform and improve obstetric blood product use.
\end{abstract}

Keywords: Blood transfusions, Obstetrics, Trends

\footnotetext{
* Correspondence: edward.jegasothy@sydney.edu.au

${ }^{1}$ Clinical and Population Perinatal Health Research, Kolling Institute, Northern

Sydney Local Health District, St Leonards, NSW, Australia

${ }^{2}$ Biostatistics Training Program, New South Wales Ministry of Health, North

Sydney, NSW, Australia

Full list of author information is available at the end of the article
}

(c) The Author(s). 2018 Open Access This article is distributed under the terms of the Creative Commons Attribution 4.0 International License (http://creativecommons.org/licenses/by/4.0/), which permits unrestricted use, distribution, and reproduction in any medium, provided you give appropriate credit to the original author(s) and the source, provide a link to the Creative Commons license, and indicate if changes were made. The Creative Commons Public Domain Dedication waiver (http://creativecommons.org/publicdomain/zero/1.0/) applies to the data made available in this article, unless otherwise stated. 


\section{Background}

There has been a global movement to reduce the usage of red blood cell transfusions and focus on patient blood management to prevent avoidable blood loss [1]. In Australia, the overall usage of red blood cells has been decreasing [2]. This decrease has been attributed to programmes designed to standardise the use of blood products, such as the implementation of patient blood management guidelines. However, rates of obstetric transfusion were still increasing up to 2010 [3]. These transfusions, given to mothers around childbirth, are primarily given as treatment following postpartum haemorrhage $(\mathrm{PPH})$ [3] and make up $3.8 \%$ of all red blood cells issued [4].

In 2015, the National Blood Authority of Australia released the Patient Blood Management Guidelines module for Obstetrics and Maternity [5]. These guidelines detailed evidence- and experience-based best practice for blood management specifically within the obstetric setting, including transfusion, detection and management of anaemia, use of recombinant activated factor VII, tranexamic acid, cell salvage and interventional radiology. Prior to this, there were no specific guidelines for obstetric transfusions in place in Australia. However, evidence for patient blood management was already in development and guidelines for Critical Bleeding and Massive Transfusion were published in 2011 [6].

The use of red blood cells in the obstetric setting is influenced by patient indications as well as clinical practice [7]. There are numerous risk factors contributing to the risk of obstetric transfusion. These include demographics and baseline health of the mother (such as maternal age, parity, previous caesarean section) as well as conditions and treatments occurring during the antenatal and peripartum period (induction of labour, instrumental delivery) [3], and these risk factors are changing over time. PPH rates have also increased [8]. While transfusion rates have been explored up until 2010, more recent trends in obstetric transfusion, and the extent to which maternal, pregnancy and birth factors may be influencing the changing rate of transfusion, are unknown.

This study aimed to assess the recent trend in red blood cell transfusion rates for mothers giving birth in hospitals in NSW, Australia, and, using two methodological approaches, the extent to which this trend can be explained by available maternal, pregnancy and birth characteristics.

\section{Methods}

\section{Study population}

The study population comprised women delivering live or stillborn infants of at least 20 weeks gestation in New South Wales (NSW) hospitals from July 2005 to June 2015. NSW is the most populous state in Australia with a population of 7.6 million residents in 2015 and accounts for approximately one third of all Australian births [9].

\section{Data sources}

Data on maternal and birth characteristics were from the Perinatal Data Collection ('birth data'), a record of all births occurring in NSW, reported by the attending midwife or doctor. The Admitted Patient Data Collection ('hospital data') provided hospital inpatient admission records including diagnoses and procedures coded with the 10th revision of the International Classification of Diseases, Australian Modification (ICD10-AM) and the Australian Classification of Health Interventions $(\mathrm{ACHI})$, respectively. These two datasets underwent probabilistic linkage by the NSW Centre for Health Record Linkage, with an estimated false positive and false negative linkage rate of less than 5 per 1000 records [10]. Datasets were provided to the researchers with identifying fields removed.

\section{Outcome}

The outcome of interest was the administration of a red blood cell transfusion during the birth admission and in postnatal hospital admissions up to six weeks after the birth (ACHI 13706-01 or 13,706-02), referred to herein as an 'obstetric transfusion'. This would have included a small number of transfusions that were administered in the birth admission but prior to delivery.

\section{Risk factors}

We identified potential maternal and pregnancy characteristics known to contribute to the risk of an obstetric transfusion through literature review and clinical experience $[3,8,11-16]$. We then assessed which of these were reliably available in the data sources. The factors were categorised as pre-pregnancy, or pregnancy and birth (Additional file 1: Table S1).

Maternal demographics, and pregnancy, labour and birth characteristics were obtained from the birth data. Acute and chronic conditions were ascertained from the hospital data, by searching diagnosis codes of the antenatal, birth and postpartum admissions. Anaemia diagnoses were identified from antenatal records only. In vitro fertilisation and intracytoplasmic sperm injection ('assisted reproductive technology') were identified if the mother was admitted to hospital with these diagnosis or procedure codes in the twelve months prior to the birth. As hospital data were only available from July 2001, previous postpartum haemorrhage and obstetric transfusion was derived from a four-year look-back period in the linked data prior to the birth. A previous validation study, which compared medical records to hospital discharge data, found that red blood cell transfusion 
(sensitivity $83.1 \%$, positive predictive value $98.8 \%$ ) and $\mathrm{PPH}$ (sensitivity $73.8 \%$, positive predictive value $83.9 \%$ ) are well reported in hospital data, though there is some under-ascertainment [17]. The use of linked hospital and births data decreases the risk of misclassification of certain characteristics compared with each of the data sources individually $[18,19]$.

Maternal socioeconomic status (SES) was derived from each mother's area of residence using the Index of Relative Socioeconomic Advantage and Disadvantage (IRSAD) from the Socioeconomic Indexes for Areas package produced by the Australian Bureau of Statistics [20]. Each area of residence was assigned a quintile of IRSAD based on population distribution.

\section{Statistical analysis}

Descriptive analyses of the outcome and risk factors were conducted by plotting rates of each by year. We used logistic regression to estimate the crude effects on the outcome of each of the risk factors as well as year of birth. Cochran-Armitage tests were also performed to assess the trend in rates of obstetric transfusions, $\mathrm{PPH}$ and each of the covariates, by year, over the study period.

We used two approaches to assess the extent to which maternal, pregnancy and birth factors could explain the temporal trends in obstetric transfusion rate. The first method assessed the trend in transfusions over time that is not explained by risk factors, and the second demonstrated the expected trend given the risk factors. Both methods used predictive logistic regression models with obstetric transfusion as the outcome while controlling for risk factors. Using these models, with maternal and pregnancy risk factors as predictors, we predicted the rates of red blood cell transfusion over the study period. If changes in maternal and pregnancy risk factors were sufficient to explain the increasing transfusion rate, this would be reflected in the close fit of the models.

In the first approach, crude odds ratios for year of birth were compared with adjusted odds ratios for year of birth from models: (a) adjusted for pre-pregnancy risk factors, and (b) adjusted for all pre-pregnancy, pregnancy and birth risk factors, which also include pregnancy complications. Pre-pregnancy factors include maternal demographics, reproductive history and existing comorbidities. The full model adjusted for all of the available pre-pregnancy, current pregnancy and birth factors. The degree to which the adjusted odds ratios moved closer to 1 compared with the crude odds ratios indicated how much of the temporal trend was explained by the risk factors.

The second method compared the change in observed rate of obstetric transfusion by year with the predicted rate of transfusion by year from a model with (a) only pre-pregnancy risk factors, and (b) all pre-pregnancy, pregnancy and birth risk factors. These models did not include year of birth as a covariate and included data from all years of the study. The relative increase in the observed rate by year compared with 2005 was calculated by dividing the observed rate in each year by the rate in 2005, thus indicating the proportional change in obstetric transfusions over time. Similarly, the predicted rate-ratios by year showed the relative expected change in rate of transfusion due to the changing distribution of risk factors over time. Both approaches assumed a consistent relationship between each of the risk factors and the outcome over the study period.

Covariates were excluded if they could not be consistently ascertained over the study period. We also examined the trends in $\mathrm{PPH}$, but because it is on the causal pathway between many of the risk factors and the outcome PPH was not included as a risk factor in the analyses. Statistical analysis was performed using SAS, version 9.3 (SAS Institute, Cary, North Carolina, United States of America).

\section{Results}

There were 939,470 births in NSW hospitals between July 2005 and June 2015. Of these, 3811 (0.4\%) births were excluded due to missing values for one or more risk factors. Among the remaining 935,659 births included in the study, mothers were found to have received an obstetric red blood cell transfusion in 14,275 (15 per 1000 births) births. This rate increased by $38.7 \%$ from 13 per 1000 births in 2005 to a peak of 17 per 1000 births in 2011 (increasing trend, $p<0.001$ ), but then remained mostly stable until 2015, remaining at 17 per 1000 births for each year apart from a drop to 16 per 1000 births in 2012 (Fig. 1). The rate of postpartum haemorrhage followed a similar trend to that of obstetric transfusion (Fig. 1) up to 2011, but continued to increase after 2011. Overall, the PPH rate increased by $54 \%$ from 74 in 2005 to 114 per 1000 births in $2015(p<0.0001)$. Of mothers receiving obstetric transfusions, $76.7 \%$ were found to have had PPH (Table 1). The proportions of mothers with several risk factors were found to have an increasing trend over the study period including mothers over 40 years of age, mothers born overseas, previous obstetric transfusions, diabetes, forceps delivery and caesarean sections, both with and without labour (all $p<0.0001$ ) (Table 1).

In unadjusted analysis, women who received obstetric transfusion were more likely to be giving birth to their first child, giving birth pre-term ( $<37$ weeks gestation) or giving birth to multiples compared with those who did not have a transfusion (Table 2). Those who had a previous $\mathrm{PPH}$ or obstetric transfusion, an inherited or acquired haematological or platelet disorder, a third or 


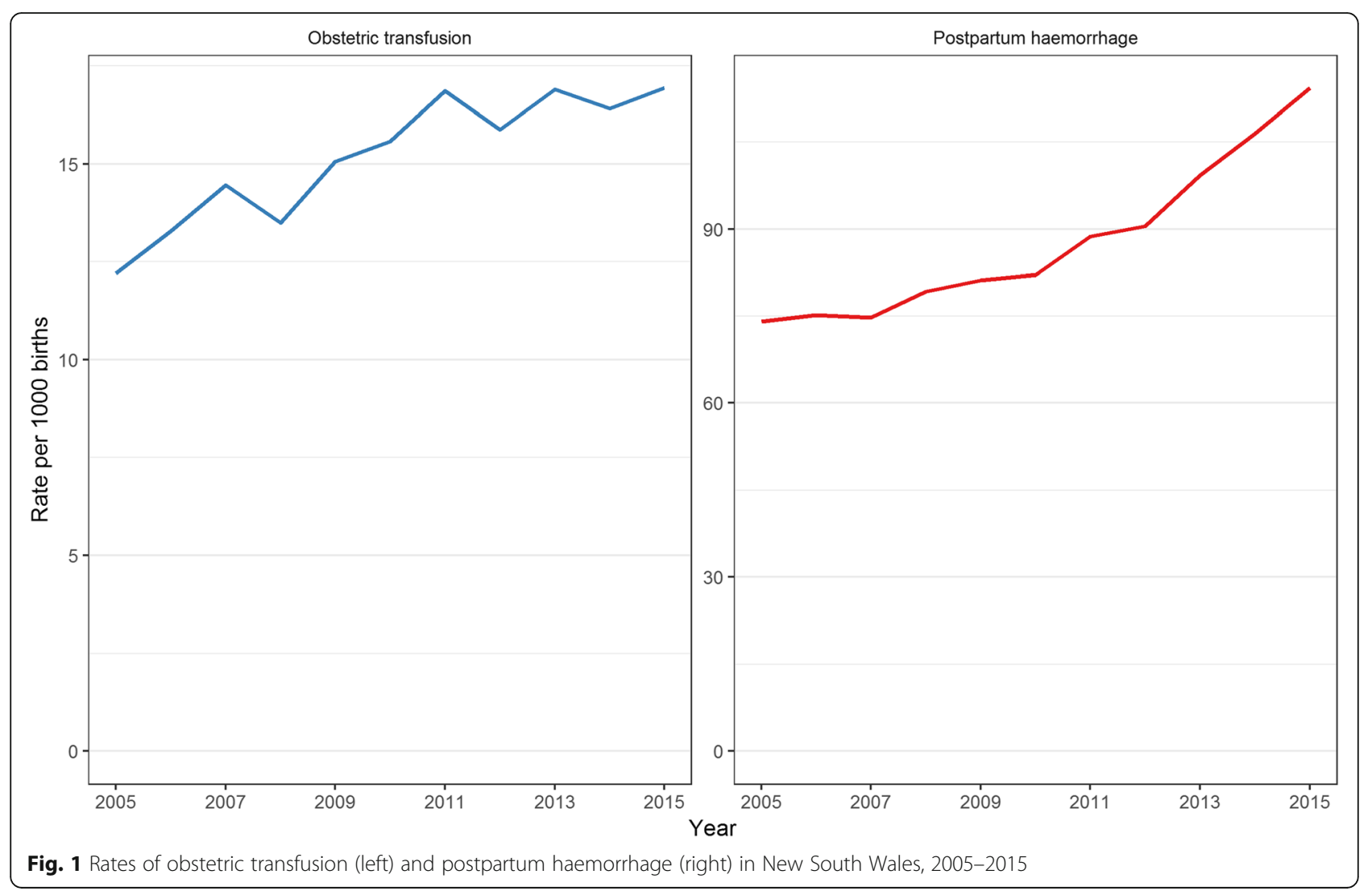

fourth degree perineal tear, an episiotomy, an antepartum haemorrhage, a large-for-gestational-age infant, any placental abnormality, higher parity $(5+)$, induced labour or hypertension, were at increased risk of transfusion. Women from lower socioeconomic status areas were more likely to receive a transfusion than those from higher socioeconomic status areas. There was no difference in risk of transfusion between mothers who had a previous caesarean or previous uterine surgery and those who did not (Table 2).

From the models which included year, if the risk factors could account for the change in rates of transfusion over time, then the odds ratios for each year in the adjusted model would be closer to 1 than the crude odds ratios. Controlling for pre-pregnancy characteristics did not change the effect estimates for year of birth meaningfully when compared with the crude estimates from 2006 to 2010, but slightly larger changes were seen in later years; crude odds ratio (OR) 1.35 (95\% confidence interval (CI) $1.22,1.49)$ to adjusted OR 1.30 (95\% CI $1.17,1.43)$ in 2014 and crude OR 1.39 (95\% CI $1.25,1.56)$ to adjusted OR 1.34 (95\% CI $1.20,1.50)$ in 2015 (Table 2). Additional inclusion of pregnancy and birth characteristics saw a further reduction in odds ratios for each of the years. The crude OR for obstetric transfusion comparing 2015 with 2005 was 1.39
(95\% CI 1.25, 1.56). This dropped slightly to 1.34 (95\% CI 1.20, 1.50) after adjusting for the maternal and pre-pregnancy factors, and further to 1.29 (95\% CI $1.15,1.45)$ when controlling for all available covariates (Table 2).

The same pattern is shown graphically in Fig. 2 which presents the predicted and observed rate ratios relative to 2005. Considering only pre-pregnancy risk factors, the rate of obstetric transfusion was only expected to rise by $4.1 \%$ from 2005 to 2015 (Fig. 2). When including pregnancy and birth risk factors, the expected increase in obstetric transfusion was predicted to be $10.3 \%$. However, there was a $38.7 \%$ observed increase in rate over the same period (Fig. 2). The period during which the largest increases in transfusion rate were predicted, in each model, was 2011 to 2015 . This is the same period in which the observed rate did not increase.

\section{Discussion}

We found that, among births in NSW hospitals, the rate of obstetric transfusions increased by $38.7 \%$ between 2005 and 2011, from 13 to 17 per 1000 births, but remained relatively stable from 2011 to 2015 . The two methodological approaches used both revealed that the change in rate of obstetric transfusions could only be partly explained by the available known maternal and 
Table 1 Maternal and pregnancy characteristics of women giving birth in New South Wales hospitals, 2005-2015, for those with and without obstetric transfusion and by year

\begin{tabular}{|c|c|c|c|c|c|c|}
\hline & Obstetric transfusion & $\begin{array}{l}\text { No obstetric } \\
\text { transfusion }\end{array}$ & $2005-06$ & $2014-15$ & \multirow{3}{*}{$\begin{array}{l}\text { Trend test }{ }^{\mathrm{b}} \\
p\end{array}$} \\
\hline & & \multicolumn{2}{|l|}{ N (per 1000 births) } & \multicolumn{2}{|c|}{ Prevalence $^{c}$ (per 1000 births) } & \\
\hline & Total & $N=14,275$ & $N=921,384$ & $N=88,707$ & $N=92,875$ & \\
\hline \multirow[t]{33}{*}{ Pre-pregnancy risk factors } & Maternal age & & & & & \\
\hline & $<20$ years & $740(51.8)$ & $30,356(32.9)$ & 38.2 & 26.7 & $<0.0001$ \\
\hline & $20-24$ years & $2221(155.6)$ & $122,355(132.8)$ & 142.8 & 125.0 & $<0.0001$ \\
\hline & $25-29$ years & $3751(262.8)$ & $249,994(271.3)$ & 270.6 & 272.5 & 0.001 \\
\hline & $30-34$ years & $4256(298.1)$ & $305,705(331.8)$ & 337.8 & 347.0 & $<0.0001$ \\
\hline & $35-39$ years & $2562(179.5)$ & $174,513(189.4)$ & 175.0 & 184.4 & 0.57 \\
\hline & $40+$ years & $745(52.2)$ & $38,461(41.7)$ & 35.7 & 44.4 & $<0.0001$ \\
\hline & Smoker & $1919(134.4)$ & $105,603(114.6)$ & 138.2 & 93.4 & $<0.0001$ \\
\hline & Parity & & & & & \\
\hline & $1 s t$ & $7417(519.6)$ & $394,021(427.6)$ & 415.4 & 438.9 & $<0.0001$ \\
\hline & 2nd & $3520(246.6)$ & $309,134(335.5)$ & 334.5 & 340.6 & 0.88 \\
\hline & $3 \mathrm{rd}$ & $1763(123.5)$ & $136,140(147.8)$ & 155.6 & 139.0 & $<0.0001$ \\
\hline & 4 th & $791(55.4)$ & $48,837(53.0)$ & 57.1 & 48.2 & $<0.0001$ \\
\hline & $5+$ & $784(54.9)$ & $33,252(36.1)$ & 37.3 & 33.4 & $<0.0001$ \\
\hline & Multiple birth & $658(46.1)$ & $13,214(14.3)$ & 16.0 & 14.6 & 0.0047 \\
\hline & Australian born & $9231(646.7)$ & $621,316(674.3)$ & 719.8 & 635.6 & $<0.0001$ \\
\hline & Assisted reproductive technology & $571(40.0)$ & $24,078(26.1)$ & 20.9 & 28.2 & $<0.0001$ \\
\hline & Previous obstetric transfusion & $491(34.4)$ & $7346(8.0)$ & 4.4 & 11.5 & $<0.0001$ \\
\hline & Previous PPH & $1349(94.5)$ & $45,633(49.5)$ & 31.9 & 64.0 & $<0.0001$ \\
\hline & Previous caesarean or uterine scar & $2185(153.1)$ & $145,638(158.1)$ & 143.7 & 165.2 & $<0.0001$ \\
\hline & Pregestational diabetes & $105(5.5)$ & $5040(5.5)$ & 5.1 & 7.5 & $<0.0001$ \\
\hline & Pregestational hypertension & $242(11.1)$ & $10,191(11.1)$ & 12.5 & 10.8 & 0.01 \\
\hline & Any chronic condition ${ }^{a}$ & $847(59.3)$ & $22,005(23.9)$ & 34.7 & 26.4 & $<0.0001$ \\
\hline & Blood/platelet disorder & $1642(115.0)$ & $9118(9.9)$ & 12.5 & 13.5 & 0.078 \\
\hline & Morbid obesity & $157(11.0)$ & $5148(5.6)$ & 2.5 & 9.5 & $<0.0001$ \\
\hline & Private hospital/insurance & $3033(212.5)$ & $307,650(333.9)$ & 326.3 & 323.6 & $<0.0001$ \\
\hline & Quintile of socioeconomic status & & & & & \\
\hline & Lowest quintile & $3448(241.5)$ & $193,810(210.3)$ & 218.4 & 209.3 & $<0.0001$ \\
\hline & Second quintile & $3246(227.4)$ & $184,444(200.2)$ & 199.5 & 208.2 & $<0.0001$ \\
\hline & Middle quintile & 2907 (203.6) & $177,755(192.9)$ & 190.8 & 195.4 & 0.0001 \\
\hline & Fourth quintile & $2528(177.1)$ & $177,314(192.4)$ & 186.2 & 195.9 & $<0.0001$ \\
\hline & Highest quintile & $1987(139.2)$ & $178,375(193.6)$ & 196.0 & 183.9 & $<0.0001$ \\
\hline & Area of residence unknown & $159(11.1)$ & $9686(10.5)$ & 9.0 & 7.2 & $<0.0001$ \\
\hline \multirow{8}{*}{$\begin{array}{l}\text { Pregnancy and birth } \\
\text { risk factors }\end{array}$} & Anaemia in pregnancy & $197(13.8)$ & $2949(3.2)$ & 1.9 & 8.0 & $<0.0001$ \\
\hline & Antepartum haemorrhage & $727(50.9)$ & $21,823(23.7)$ & 24.0 & 26.7 & $<0.0001$ \\
\hline & Postpartum haemorrhage & $10,947(766.9)$ & $70,633(76.7)$ & 73.8 & 111.6 & $<0.0001$ \\
\hline & Placenta praevia & $1076(75.4)$ & $9277(10.1)$ & 10.0 & 11.1 & 0.13 \\
\hline & Placental abruption & $545(38.2)$ & $4143(4.5)$ & 4.8 & 5.5 & 0.0073 \\
\hline & Morbidly adherent placenta & $724(50.7)$ & $1675(1.8)$ & 2.3 & 3.1 & 0.0498 \\
\hline & Retained placental tissue & $105(7.4)$ & $4316(4.7)$ & 5.7 & 3.3 & $<0.0001$ \\
\hline & Uterine rupture & $129(9.0)$ & $345(0.4)$ & 0.6 & 0.5 & 0.18 \\
\hline
\end{tabular}


Table 1 Maternal and pregnancy characteristics of women giving birth in New South Wales hospitals, 2005-2015, for those with and without obstetric transfusion and by year (Continued)

\begin{tabular}{|c|c|c|c|c|c|}
\hline & Obstetric transfusion & $\begin{array}{l}\text { No obstetric } \\
\text { transfusion }\end{array}$ & $2005-06$ & $2014-15$ & Trend test ${ }^{b}$ \\
\hline & \multicolumn{2}{|l|}{ N (per 1000 births) } & \multicolumn{2}{|c|}{ Prevalence $^{c}$ (per 1000 births) } & $p$ \\
\hline Uterine fibroid & $79(5.5)$ & $1302(1.4)$ & 2.8 & 1.2 & $<0.0001$ \\
\hline Pregnancy diabetes & $1097(76.8)$ & $62,109(67.4)$ & 48.6 & 119.4 & $<0.0001$ \\
\hline Pregnancy hypertension & $2051(143.7)$ & $72,579(78.8)$ & 85.8 & 79.1 & $<0.0001$ \\
\hline \multicolumn{6}{|l|}{ Gestational age } \\
\hline 20-32 weeks & $835(58.5)$ & $13,687(14.9)$ & 15.3 & 16.3 & 0.68 \\
\hline 33-36 weeks & $1404(98.4)$ & $47,079(51.1)$ & 49.5 & 54.7 & $<0.0001$ \\
\hline $37-41$ weeks & $11,874(831.8)$ & $853,244(926.0)$ & 917.8 & 925.2 & $<0.0001$ \\
\hline $42+$ weeks & $162(11.3)$ & $7374(8.0)$ & 17.4 & 3.8 & $<0.0001$ \\
\hline Large for gestational age & $2150(849.4)$ & $92,783(100.7)$ & 97.1 & 97.3 & $<0.0001$ \\
\hline \multicolumn{6}{|l|}{ Mode of birth } \\
\hline Normal vaginal delivery & $6115(428.4)$ & $536,899(582.7)$ & 609.3 & 562.0 & $<0.0001$ \\
\hline Forceps & $1457(102.1)$ & $35,638(38.7)$ & 31.6 & 47.5 & $<0.0001$ \\
\hline Vacuum & $1394(97.7)$ & $65,074(70.6)$ & 69.7 & 65.5 & $<0.0001$ \\
\hline Vaginal breech & $110(7.7)$ & $3338(3.6)$ & 3.6 & 3.8 & 0.83 \\
\hline Caesarean with labour & $2540(177.9)$ & $115,015(124.8)$ & 116.9 & 126.4 & $<0.0001$ \\
\hline Caesarean without labour & $2659(186.3)$ & $165,420(179.5)$ & 168.8 & 194.7 & $<0.0001$ \\
\hline \multicolumn{6}{|l|}{ Onset of labour } \\
\hline Spontaneous & $6752(473.0)$ & $508,947(552.4)$ & 580.7 & 505.3 & $<0.0001$ \\
\hline Induced & $4864(340.7)$ & $247,007(268.1)$ & 250.5 & 300.0 & $<0.0001$ \\
\hline No labour & $2659(186.3)$ & $165,430(179.5)$ & 168.8 & 194.7 & $<0.0001$ \\
\hline 3rd/4th degree perineal tear & $969(67.9)$ & $18,820(20.4)$ & 18.3 & 23.8 & $<0.0001$ \\
\hline Episiotomy & $2950(206.7)$ & $115,758(125.6)$ & 115.0 & 142.6 & $<0.0001$ \\
\hline Cervical laceration & $248(17.4)$ & $554(0.6)$ & 0.7 & 1.1 & 0.0013 \\
\hline
\end{tabular}

${ }^{a}$ Chronic conditions include, psychiatric, renal, cardiovascular, autoimmune, respiratory and thyroid illnesses

${ }^{\mathrm{b}}$ Cochran-Armitage trend test for prevalence of risk factor over years 2005 to 2015

'Prevalence of risk factor among births 1 July 2005 to 30 June 2006 and 1July 2014 to 30 June 2015

pregnancy risk factors. Method 1, comparing crude and adjusted odds ratios, showed that the year effect could not be removed by adjusting for maternal and pregnancy factors. In Method 2, pre-pregnancy risk factors predicted a small, $4.1 \%$, increase in the obstetric transfusion rate. Inclusion of pregnancy and birth factors predicted a larger, $10.3 \%$ increase in the rate, but not to the extent that was observed. The majority (76.7\%) of obstetric transfusions in the study period were found to coincide with a PPH diagnosis, the rate of which increased throughout the study period, from 74 to 114 per 1000 births.

The increase in PPH and transfusion rates observed up to 2011 is consistent with previous studies in NSW $[3,8]$. In the USA, the rate of transfusion also increased from 1998 to 2011, however PPH rates remained stable over the same period. [21] The PPH rate increased in the Netherlands from 40 per 1000 births in 2003 to 66/ 1000 in 2011 but appeared to plateau from 2011 to 64/
1000 in 2013 [22] and in Canada the rate increased by $21 \%$ from $51 / 1000$ in $2003-2004$ to $6.1 / 1000$ births in 2009-2010 [15].

This is the first study to report a largely stable rate of obstetric transfusions in NSW since 2011. Given that transfusion is often used as a marker of severity of haemorrhage, the stable transfusion rate in the context of increasing $\mathrm{PPH}$ is an encouraging sign. However, the obstetric transfusion rate in NSW is still higher than observed in the United States of America where there were 7 transfusions per 1000 births between 1998 and 2011 [21].

We found that pre-pregnancy characteristics, while being important risk factors for transfusion, did not contribute greatly to the change in obstetric transfusion rates over time. Accounting for all the pre-pregnancy, and pregnancy and birth factors that were ascertained, explained a larger degree of the change in transfusion rate but still only predicted a quarter of the increase observed from 2005 to 2015. Interestingly, the largest 
Table 2 Crude and adjusted odds ratios of obstetric transfusion in women giving birth in New South Wales hospitals, 2005-2015 (Method 1)

\begin{tabular}{|c|c|c|c|}
\hline & \multirow[t]{2}{*}{ Crude odds ratios (95\% Cl) } & \multicolumn{2}{|c|}{ Adjusted odds ratios $(95 \% \mathrm{Cl})$} \\
\hline & & Pre-pregnancy & Full model \\
\hline \multicolumn{4}{|l|}{ Year of birth } \\
\hline 2005 & Ref & Ref & Ref \\
\hline 2006 & $1.09(0.98,1.21)$ & $1.08(0.98,1.20)$ & $1.09(0.98,1.21)$ \\
\hline 2007 & $1.19(1.07,1.31)$ & $1.19(1.07,1.32)$ & $1.16(1.05,1.29)$ \\
\hline 2008 & $1.10(1.00,1.22)$ & $1.12(1.01,1.23)$ & $1.09(0.98,1.21)$ \\
\hline 2009 & $1.24(1.12,1.36)$ & $1.27(1.15,1.40)$ & $1.26(1.13,1.39)$ \\
\hline 2010 & $1.28(1.16,1.41)$ & $1.30(1.18,1.44)$ & $1.29(1.16,1.43)$ \\
\hline 2011 & $1.38(1.25,1.53)$ & $1.40(1.27,1.55)$ & $1.37(1.24,1.52)$ \\
\hline 2012 & $1.30(1.18,1.44)$ & $1.29(1.17,1.43)$ & $1.26(1.14,1.39)$ \\
\hline 2013 & $1.39(1.26,1.53)$ & $1.36(1.23,1.50)$ & $1.34(1.21,1.48)$ \\
\hline 2014 & $1.35(1.22,1.49)$ & $1.30(1.17,1.43)$ & $1.27(1.14,1.40)$ \\
\hline 2015 & $1.39(1.25,1.56)$ & $1.34(1.20,1.50)$ & $1.29(1.15,1.45)$ \\
\hline \multicolumn{4}{|l|}{ Maternal age } \\
\hline$<20$ years & $1.34(1.23,1.46)$ & $1.20(1.10,1.31)$ & $1.33(1.22,1.45)$ \\
\hline 20-24 years & Ref & Ref & Ref \\
\hline $25-29$ years & $0.83(0.78,0.87)$ & $0.93(0.88,0.98)$ & $0.86(0.81,0.91)$ \\
\hline 30-34 years & $0.77(0.73,0.81)$ & $0.99(0.93,1.04)$ & $0.87(0.82,0.92)$ \\
\hline $35-39$ years & $0.81(0.76,0.86)$ & $1.08(1.01,1.15)$ & $0.90(0.84,0.96)$ \\
\hline $40+$ years & $1.07(0.98,1.16)$ & $1.31(1.20,1.44)$ & $1.06(0.97,1.17)$ \\
\hline Smoke & $1.20(1.14,1.26)$ & $1.02(0.97,1.08)$ & $1.01(0.96,1.07)$ \\
\hline \multicolumn{4}{|l|}{ Parity } \\
\hline $1 \mathrm{st}$ & Ref & Ref & Ref \\
\hline 2nd & $0.60(0.58,0.63)$ & $0.54(0.51,0.56)$ & $0.77(0.73,0.81)$ \\
\hline $3 \mathrm{rd}$ & $0.69(0.65,0.72)$ & $0.58(0.55,0.62)$ & $0.87(0.82,0.92)$ \\
\hline 4 th & $0.86(0.80,0.93)$ & $0.67(0.62,0.72)$ & $0.98(0.90,1.07)$ \\
\hline $5+$ & $1.25(1.16,1.35)$ & $0.86(0.79,0.93)$ & $1.21(1.10,1.32)$ \\
\hline Multiple & $3.32(3.07,3.60)$ & $2.94(2.71,3.20)$ & $2.50(2.28,2.74)$ \\
\hline Australian born & $0.88(0.85,0.91)$ & $0.91(0.88,0.94)$ & $0.89(0.86,0.92)$ \\
\hline Assisted reproductive technology & $1.55(1.43,1.69)$ & $1.66(1.52,1.82)$ & $1.47(1.33,1.61)$ \\
\hline Previous obstetric transfusion & $4.66(4.17,5.20)$ & $3.00(2.64,3.42)$ & $2.73(2.38,3.13)$ \\
\hline Previous postpartum haemorrhage & $1.98(1.85,2.12)$ & $1.88(1.73,2.04)$ & $1.82(1.68,1.98)$ \\
\hline Uterine scar & $0.96(0.92,1.01)$ & $1.27(1.20,1.33)$ & $1.08(1.02,1.16)$ \\
\hline Pregestational diabetes & $1.35(1.11,1.64)$ & $0.97(0.79,1.19)$ & $0.78(0.63,0.95)$ \\
\hline Pregestational hypertension & $1.54(1.36,1.75)$ & $1.22(1.06,1.39)$ & $0.99(0.86,1.13)$ \\
\hline Chronic condition & $2.58(2.40,2.77)$ & $1.74(1.61,1.88)$ & $1.64(1.51,1.77)$ \\
\hline Blood disorder & $13.01(12.31,13.75)$ & $11.31(10.68,11.98)$ & $10.37(9.76,11.02)$ \\
\hline Morbid obesity & $1.98(1.69,2.32)$ & $1.41(1.20,1.67)$ & $1.26(1.07,1.50)$ \\
\hline Private insurance & $0.54(0.52,0.56)$ & $0.56(0.53,0.58)$ & $0.56(0.54,0.59)$ \\
\hline \multicolumn{4}{|l|}{ Quintile of socioeconomic status } \\
\hline Most disadvantaged quintile & Ref & Ref & Ref \\
\hline Second quintile & $0.99(0.94,1.04)$ & $1.03(0.98,1.08)$ & $1.02(0.97,1.07)$ \\
\hline Middle quintile & $0.92(0.87,0.97)$ & $1.01(0.95,1.06)$ & $0.95(0.90,1.00)$ \\
\hline
\end{tabular}


Table 2 Crude and adjusted odds ratios of obstetric transfusion in women giving birth in New South Wales hospitals, 2005-2015 (Method 1) (Continued)

\begin{tabular}{|c|c|c|c|}
\hline & \multirow[t]{2}{*}{ Crude odds ratios $(95 \% \mathrm{Cl})$} & \multicolumn{2}{|c|}{ Adjusted odds ratios $(95 \% \mathrm{Cl})$} \\
\hline & & Pre-pregnancy & Full model \\
\hline Fourth quintile & $0.80(0.76,0.84)$ & $0.88(0.83,0.93)$ & $0.85(0.80,0.90)$ \\
\hline Most advantaged quintile & $0.63(0.59,0.66)$ & $0.75(0.70,0.79)$ & $0.72(0.68,0.77)$ \\
\hline Area of residence unknown & $0.92(0.79,1.08)$ & $0.91(0.78,1.07)$ & $0.96(0.81,1.13)$ \\
\hline Pregnancy anaemia & $4.36(3.77,5.04)$ & - & $1.20(1.02,1.42)$ \\
\hline Antepartum haemorrhage & $2.21(2.05,2.39)$ & - & $1.22(1.12,1.32)$ \\
\hline Placenta praevia & $8.02(7.51,8.56)$ & - & $6.89(6.35,7.49)$ \\
\hline Placental abruption & $8.79(8.03,9.63)$ & - & $5.60(5.04,6.22)$ \\
\hline Morbidly adherent placenta & $29.34(26.84,32.06)$ & - & $22.08(19.87,24.53)$ \\
\hline Retained placental tissue & $1.57(1.30,1.91)$ & - & $0.88(0.71,1.09)$ \\
\hline Uterine rupture & $24.35(19.88,29.83)$ & - & $18.63(14.76,23.52)$ \\
\hline Uterine fibroids & $3.94(3.14,4.95)$ & - & $3.21(2.49,4.13)$ \\
\hline Gestational diabetes & $1.15(1.08,1.23)$ & - & $0.90(0.84,0.97)$ \\
\hline Gestational hypertension & $1.96(1.87,2.06)$ & - & $1.46(1.38,1.54)$ \\
\hline \multicolumn{4}{|l|}{ Gestational age } \\
\hline 20-32 weeks & $4.39(4.08,4.71)$ & - & $2.09(1.91,2.29)$ \\
\hline 33-36 weeks & $2.14(2.03,2.27)$ & - & $1.28(1.20,1.37)$ \\
\hline 37-41 weeks & Ref & - & Ref \\
\hline $42+$ weeks & $1.58(1.35,1.85)$ & - & $1.38(1.17,1.62)$ \\
\hline Large for gestational age & $1.58(1.51,1.66)$ & - & $1.62(1.54,1.70)$ \\
\hline \multicolumn{4}{|l|}{ Mode of delivery } \\
\hline Normal vaginal & Ref & - & Ref \\
\hline Caesarean with labour & $1.94(1.85,2.03)$ & - & $1.60(1.52,1.69)$ \\
\hline Caesarean without labour & $1.41(1.35,1.48)$ & - & $1.06(0.99,1.13)$ \\
\hline Forceps & $3.59(3.39,3.80)$ & - & $2.19(2.03,2.36)$ \\
\hline Vacuum & $1.88(1.77,1.99)$ & - & $1.56(1.46,1.67)$ \\
\hline Vaginal breech & $2.89(2.39,3.50)$ & - & $1.29(1.04,1.59)$ \\
\hline Induced delivery & $1.41(1.36,1.46)$ & - & $1.26(1.21,1.31)$ \\
\hline $3 \mathrm{rd}$ of 4 th degree perineal tear & $3.49(3.27,3.73)$ & - & $2.82(2.62,3.03)$ \\
\hline Episiotomy & $1.81(1.74,1.89)$ & - & $1.53(1.44,1.62)$ \\
\hline Cervical laceration & $29.40(25.28,34.18)$ & - & $24.75(20.96,29.22)$ \\
\hline
\end{tabular}

predicted increases in transfusion, with each model, were seen between 2010 and 2015 when the observed rate remained stable. This means that the rate of obstetric transfusion did not increase during this period despite an overall increase in maternal risk factors for obstetric transfusion. Our findings indicate that changes in rates of obstetric transfusion are largely influenced by other unmeasured factors which may include clinical decision making, policy changes, and the unpredictable nature of $\mathrm{PPH}$ as it is understood that many women who experience $\mathrm{PPH}$ do not possess any identifiable risk factors [23]. The diagnosis of $\mathrm{PPH}$, based on an estimation of blood loss, and the decision to transfuse are both dependent on perceptions and experience of the attending clinicians as well as the hospital practice and blood supply [7, 11]. Furthermore, the combination of factors prompting intervention, relationships between risk factors or changing management of factors such as induction of labour may have played a role in obstetric transfusion trends.

While the new Patient Blood Management guidelines for Obstetrics and Maternity were only released in 2015 [5], the general movement away from transfusion-based management to patient-based management had been in progress for a number of years prior. The first module of the guidelines for patient blood management in the 


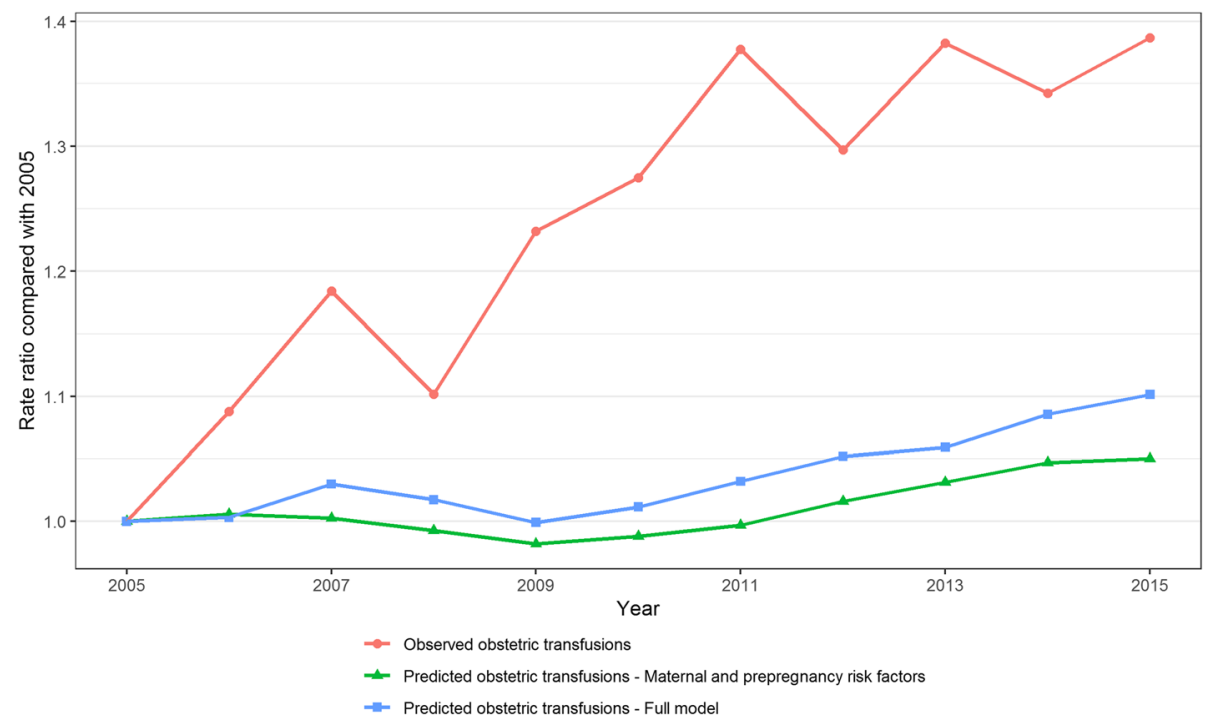

Fig. 2 Observed and predicted obstetric transfusion rate-ratios comparing each year with 2005 (Method 2)

context of Critical Bleeding and Massive Transfusion was released in 2011 and included some recommendations for maternal care in the area of massive transfusion [6]. This is the same year that the rates of transfusion in the study appeared to peak. The guidelines included treatment paths to reduce transfusion for any critically bleeding or trauma hospital patient and reflected the movement towards reduced use of blood products to reduce unnecessary risk associated with this exposure. Specific recommendations regarding pharmacotherapy include the use of recombinant activated Factor VII [6].

Alongside new guidelines, other treatments for $\mathrm{PPH}$ and anaemia have been approved by the Australian Therapeutic Goods Authority (ATGA) and came into clinical practice during the study period, which may have contributed to the stable obstetric transfusion rate. These include tranexamic acid, recombinant activated Factor VII and ferric carboxymaltose (Ferinject). Intravenous tranexamic acid, an antifibrinolytic agent, was approved by ATGA in 2010 to reduce blood loss in cardiac and orthopaedic surgical patients [24]. However, studies since 2001 suggest that tranexamic acid has a role in reducing bleeding and risk of transfusion in postpartum haemorrhage [25-28], such that WHO updated its guideline for management of postpartum haemorrhage to include tranexamic acid in 2012 [29, 30]. Furthermore, the publication of the WOMBAT trial in 2017 and subsequent updates in $\mathrm{PPH}$ guidelines for tranexamic acid to be part of standard management, will potentially lead to a reduction in $\mathrm{PPH}$ and transfusion rates in the future [31]. Recombinant activated Factor VII is used in Australia to prevent, slow or stop bleeding $[32,33]$. Ferric carboxymaltose, introduced in Australia in 2011, is an intravenous infusion given to treat iron deficiency that has advantages over previously available iron treatments including reduced side effects and easier administration [34, 35]. The increased use of such treatments could potentially have had an impact on the rate of transfusions administered to mothers in response to anaemia and haemorrhage; however, this information is not collected in routinely collected birth or hospital data. Further research into specific blood management treatments and variation in practice by hospital may better explain the changes in trends in transfusion over time and point to the potential for improvements in practice to encourage further safe reductions in the use of blood products.

The main strengths of our study were the size and completeness of the dataset as well as the high-quality linked data from both the perinatal and hospital data. All births in NSW hospitals were included in the study with only $0.4 \%$ being excluded from the analysis due to missing data. This allowed us to investigate rare risk factors and treatments. While PPH and transfusion codes have been found to be reliable, changes in ascertainment may play a small part in changes in reported rates. This study also used two approaches to answer the study question which provided similar results, strengthening the conclusions. There were, however, some key covariates that are not well reported in either dataset, including body mass index, a change in which over time may have contributed to the changing rate of transfusions. The hospital data did not include laboratory results such as haemoglobin, which may have helped indicate the appropriateness of red blood cell transfusion. We were also limited by our inability to include prior obstetric history 
of mothers before the availability of linked data in July 2001. While we have taken into account risk factors related to transfusion, particularly in the predicted versus observed analysis, we have assumed the relationship between these factors and risk of transfusion has not changed over time. However, induction of labour (for example) may be more or less likely to result in PPH and transfusion at the beginning compared to the end of our study period.

\section{Conclusion}

The rate of obstetric transfusion among NSW hospitalbased births increased over the period of 2005 to 2011 but has since stabilised through to 2015. Meanwhile, the rate of postpartum haemorrhage continued to rise from 2005 through to 2015 . The changes in rate of transfusion could only be partly explained by changes in maternal and pregnancy risk factors using each of the methods employed in this study. Further monitoring and investigation, especially following the implementation of specific patient blood management guidelines for obstetrics in 2015, will give deeper insight into these trends to assist policy makers and clinicians to improve bestpractice administration of blood products in an obstetric setting.

\section{Additional file}

Additional file 1: Table S1. Maternal and pregnancy risk factors for obstetric transfusion and sources. (DOCX $18 \mathrm{~kb}$ )

\begin{abstract}
Abbreviations
ACHI: Australian Classification of Health Interventions; Cl: Confidence interval; ICD10-AM: 10th revision of the International Classification of Diseases, Australian Modification; IRSAD: Index of Relative Socioeconomic Advantage and Disadvantage; NSW: New South Wales; PPH: Postpartum haemorrhage; SES: Socioeconomic status
\end{abstract}

\begin{abstract}
Acknowledgements
We thank the NSW Ministry of Health for access to the population health data and the Centre for Health Record Linkage for linkage of the data sets. This work was completed while EJ was employed as a trainee on the Biostatistics Training Program funded by the NSW Ministry of Health. He undertook this work while based at the Kolling Institute.
\end{abstract}

\section{Funding}

We acknowledge funding from a NSW Health Population Health and Health Services Research Support grant and National Health and Medical Research Council Partnership grant with The Australian Red Cross Blood Service and NSW Health (\#1094822). Australian governments fund the Australian Red Cross Blood Service for the provision of blood, blood products and services to the Australian community.

\section{Availability of data and materials}

The data that support the findings of this study are available from the NSW Ministry of Health but restrictions apply to the availability of these data, which were used under license for the current study, and so are not publicly available. Data may be requested from the Centre for Health Records Linkage.

\section{Authors' contributions}

$J F, J P, D R$, JS and EJ contributed to the design of the study. EJ collated and analysed the data and drafted the manuscript. EJ, JF, JP, DR, JS, TN and DI contributed to the interpretation of the analyses and revision of the article. All authors read and approved the final manuscript.

\section{Ethics approval and consent to participate}

Ethical approval for this study was obtained from the NSW Population and Health Services Research Ethics Committee (HREC/12/CIPHS/7).

\section{Consent for publication}

Not applicable.

\section{Competing interests}

The authors declare that they have no competing interests.

\section{Publisher's Note}

Springer Nature remains neutral with regard to jurisdictional claims in published maps and institutional affiliations.

\section{Author details}

${ }^{1}$ Clinical and Population Perinatal Health Research, Kolling Institute, Northern Sydney Local Health District, St Leonards, NSW, Australia. ${ }^{2}$ Biostatistics Training Program, New South Wales Ministry of Health, North Sydney, NSW, Australia. ${ }^{3}$ Sydney Medical School Northern, University of Sydney, St Leonards, NSW, Australia. ${ }^{4}$ Department of Obstetrics and Gynaecology, Royal North Shore Hospital, St Leonards, NSW, Australia. ${ }^{5}$ Sydney School of Public Health, University of Sydney, Sydney, NSW, Australia. ${ }^{6}$ Australian Red Cross Blood Service, Sydney, NSW, Australia.

Received: 27 April 2018 Accepted: 30 October 2018

Published online: 16 November 2018

References

1. Shander A, Isbister J, Gombotz H. Patient blood management: the global view. Transfusion. 2016;56(Suppl 1):S94-102.

2. NBA: National Blood Authority Annu Rep 2013-14. In. Canberra, Australia: National Blood Authority; 2014.

3. Patterson JA, Roberts $\mathrm{CL}$, Bowen JR, Irving DO, Isbister JP, Morris JM, Ford JB. Blood transfusion during pregnancy, birth, and the postnatal period. Obstet Gynecol. 2014;123(1):126-33.

4. Shortt J, Polizzotto MN, Waters N, Borosak M, Moran M, Comande M, Devine A, Jolley DJ, Wood EM. Assessment of the urgency and deferability of transfusion to inform emergency blood planning and triage: the bloodhound prospective audit of red blood cell use. Transfusion. 2009; 49(11):2296-303.

5. NBA: Patient Blood Management Guidelines: Module 5 - Obstetrics and Maternity. In. Canberra, Australia: National Blood Authority; 2015.

6. NBA: Patient Blood Management Guidelines: Module 1 - Critical Bleeding / Massive Transfusion. In. Canberra, Australia: National Blood Authority; 2011.

7. Mayson E, Shand AW, Ford JB. Single-unit transfusions in the obstetric setting: a qualitative study. Transfusion. 2016;56(7):1716-22.

8. Ford JB, Patterson JA, Seeho SK, Roberts CL. Trends and outcomes of postpartum haemorrhage, 2003-2011. BMC pregnancy and childbirth. 2015;15:334

9. AlHW: Australia's mothers and babies 2014-in brief. In. Canberra: AlHW; 2016.

10. Centre for Health Record Linkage: Master Linkage Key Qual Assur In: 2012

11. Patterson JA, Roberts $C L$, Isbister JP, Irving DO, Nicholl MC, Morris JM, Ford JB. What factors contribute to hospital variation in obstetric transfusion rates? Vox Sang. 2015;108(1):37-45.

12. Nyflot LT, Sandven I, Stray-Pedersen B, Pettersen S, Al-Zirqi I, Rosenberg M, Jacobsen AF, Vangen S. Risk factors for severe postpartum hemorrhage: a case-control study. BMC pregnancy and childbirth. 2017;17(1):17.

13. Wikkelso AJ, Hjortoe S, Gerds TA, Moller AM, Langhoff-Roos J. Prediction of postpartum blood transfusion--risk factors and recurrence. The journal of maternal-fetal \& neonatal medicine : the official journal of the European Association of Perinatal Medicine, the Federation of Asia and Oceania Perinatal Societies, the International Society of Perinatal Obstet. 2014;27(16): $1661-7$. 
14. Kramer MS, Berg C, Abenhaim H, Dahhou M, Rouleau J, Mehrabadi A, Joseph KS. Incidence, risk factors, and temporal trends in severe postpartum hemorrhage. Am J Obstet Gynecol. 2013;209(5):449.e1-7.

15. Mehrabadi A, Liu S, Bartholomew S, Hutcheon JA, Kramer MS, Liston RM, Joseph KS. Temporal trends in postpartum hemorrhage and severe postpartum hemorrhage in Canada from 2003 to 2010. J Obstet Gynaecol Can. 2014;36(1):21-33.

16. Mousa HA, Blum J, Abou El Senoun G, Shakur H, Alfirevic Z. Treatment for primary postpartum haemorrhage. The Cochrane database of systematic reviews. 2014;2:CD003249.

17. Lain SJ, Roberts CL, Hadfield RM, Bell JC, Morris JM. How accurate is the reporting of obstetric haemorrhage in hospital discharge data? A validation study. Aust N Z J Obstet Gynaecol. 2008;48(5):481-4.

18. Patterson JA, Roberts CL, Taylor LK, Ford JB. Reporting postpartum haemorrhage with transfusion: a comparison of NSW birth and hospital data. New South Wales Public Health Bulletin. 2014;24(4):153-8.

19. Roberts $\mathrm{CL}$, Algert CS, Ford JB. Methods for dealing with discrepant records in linked population health datasets: a cross-sectional study. BMC Health Serv Res. 2007;7(1):12.

20. Census of Population and Housing: Socio-Economic Indexes for Areas (SEIFA), Australia, 2011 [http://www.abs.gov.au/ausstats/abs@.nsf/mf/2033.0. 55.001].

21. Merriam AA, Wright JD, Siddiq Z, D'Alton ME, Friedman AM, Ananth CV Bateman BT. Risk for postpartum hemorrhage, transfusion, and hemorrhagerelated morbidity at low, moderate, and high volume hospitals. The journal of maternal-fetal \& neonatal medicine : the official journal of the European Association of Perinatal Medicine, the Federation of Asia and Oceania Perinatal Societies, the International Society of Perinatal Obstet. 2017:1-10.

22. van Stralen G, von Schmidt Auf Altenstadt JF, Bloemenkamp KW, van Roosmalen J, Hukkelhoven CW. Increasing incidence of postpartum hemorrhage: the Dutch piece of the puzzle. Acta Obstet Gynecol Scand. 2016;95(10):1104-10

23. Bateman BT, Berman MF, Riley LE, Leffert LR. The epidemiology of postpartum hemorrhage in a large, nationwide sample of deliveries. Anesth Analg. 2010;110(5):1368-73.

24. Therapeutic Goods Administration: Australian Public Assessment Report for Tranexamic acid. In. ACT, Australia; 2010.

25. Heesen M, Bohmer J, Klohr S, Rossaint R, van de Velde M, Dudenhausen JW Straube S. Prophylactic tranexamic acid in parturients at low risk for postpartum haemorrhage: systematic review and meta-analysis. Acta Anaesthesiol Scand. 2014;58(9):1075-85.

26. Sentilhes L, Lasocki S, Ducloy-Bouthors AS, Deruelle P, Dreyfus M, Perrotin F, Goffinet F, Deneux-Tharaux C. Tranexamic acid for the prevention and treatment of postpartum haemorrhage. Br J Anaesth. 2015;114(4):576-87.

27. Yang $\mathrm{H}$, Zheng $\mathrm{S}$, Shi $\mathrm{C}$. Clinical study on the efficacy of tranexamic acid in reducing postpartum blood lose: a randomized, comparative, multicenter trial. Zhonghua Fu Chan Ke Za Zhi. 2001;36(10):590-2.

28. Ducloy-Bouthors A-S, Jude B, Duhamel A, Broisin F, Huissoud C, Keita-Meyer H, Mandelbrot L, Tillouche N, Fontaine S, Le Goueff F, et al. High-dose tranexamic acid reduces blood loss in postpartum haemorrhage. Crit Care. 2011;15(2):R117.

29. World Health Organisation (WHO). Updated WHO Recommendation on Tranexamic Acid for the Treatment of Postpartum Haemorrhage. Switzerland: WHO; 2017.

30. World Health Organisation (WHO): WHO Recommendations for the Prevention and of Postpartum Haemorrhage. In. Switzerland: WHO; 2012.

31. Miller S, Burke T, Belizán JM, Fuchtner C, Lalonde A, Malhorta J. Tranexamic acid for post-partum haemorrhage in the WOMAN trial. Lancet. 2017; 390(10102):1583.

32. Abdul-Kadir R, McLintock C, Ducloy AS, El-Refaey $H$, England A, Federici AB, Grotegut CA, Halimeh S, Herman JH, Hofer S, et al. Evaluation and management of postpartum hemorrhage: consensus from an international expert panel. Transfusion. 2014;54(7):1756-68.

33. Zatta A, McQuilten Z, Kandane-Rathnayake R, Isbister J, Dunkley S, McNeil J, Cameron P, Phillips L. The Australian and New Zealand Haemostasis registry: ten years of data on off-licence use of recombinant activated factor VII. Blood transfusion = Trasfusione del sangue. 2015;13(1):86-99.

34. Van Wyck DB, Martens MG, Seid MH, Baker JB, Mangione A. Intravenous ferric carboxymaltose compared with oral iron in the treatment of postpartum anemia: a randomized controlled trial. Obstet Gynecol. 2007; 110(2 Pt 1):267-78.

35. Mayson E, Ampt AJ, Shand AW, Ford JB. Intravenous iron: barriers and facilitators to its use at nine maternity hospitals in New South Wales, Australia. The Australian \& New Zealand journal of obstetrics \& gynaecology. 2016;56(2):162-72.
Ready to submit your research? Choose BMC and benefit from:

- fast, convenient online submission

- thorough peer review by experienced researchers in your field

- rapid publication on acceptance

- support for research data, including large and complex data types

- gold Open Access which fosters wider collaboration and increased citations

- maximum visibility for your research: over $100 \mathrm{M}$ website views per year

At BMC, research is always in progress.

Learn more biomedcentral.com/submissions 